\title{
A Rare Case of Intradural Extramedullary Myxopapillary Ependymoma At Thoracolumbar Junction
}

\author{
Authors \\ Dr Pushkraj Baswant Birajdar, DNB Neurosurgery ${ }^{1}$ \\ Dr Syed Ameer Basha Paspala, Mch Neurosurgery ${ }^{2}$ \\ ${ }^{1}$ Government Medical College, Latur-413512, Maharashtra,India. \\ ${ }^{2}$ Care Hospital, Banjara Hills, Hyderabad-34, Telangana, India \\ Corresponding Author \\ Dr Pushkraj Baswant Birajdar, DNB Neurosurgery \\ C/O B.S.Birajdar, Sakar House, Near Jaikranti College, Sitaramnagar, \\ Latur-413512, Maharashtra, India \\ Email:pushkrajb@gmail.com
}

\begin{abstract}
A 29 year male with chronic low back pain with bilateral lower limbs paraesthesia presented in OPD. After evaluation with MRI Thoraco-Lumbar Spine found to have T12-L1 level IDEM mass compressing cauda equina? Schwanoma. He was posted for surgery and total excision of mass done with uneventful post-op period. On histopathological examination it was diagnosed as Myxopapillary Ependymoma. This is rare variant of such tumor in view of rare location and rare clinical presentation.

Keywords-Paraesthesia, MRI spine, IDEM, Cauda Equina, Schwannoma, Myxopapillary Ependymoma.
\end{abstract}

\section{Introduction}

\section{A. Clinical Case}

A 29 year male, presented with -

- H/o low back pain since 3-4 years mild in nature

- Symptomatic relief with medication, on-off episodes+

- $\mathrm{H} / 0$ bilateral lower limb radicular pain (left > right)

- $\quad$ since 3-4 months

- H/o urinary urgency since 1 week

- Tinglings in lower limbs increased since 2 days intolerable pain, difficulty in walking

\section{B. Neurological Examination}

- Conscious, coherent, Vital stable, afebrile

- Tone normal in both lower limbs

- Power in left ankle- dors flexion $4+/ 5 \&$ plantar flexion 5/5

- Rest limbs power is normal

- DTR 2+ in both lower limbs

- Planters-down going both lower limbs

- Sensory-left side graded loss of sensation below $\mathrm{T} 10$ level

- Gait-normal 


\section{Investigation}

MRI Thoraco-Lumbar Spine: s/o a well-defined idem mass lesion of sixe $1.1 \times 1.2 \times 5.8 \mathrm{~cm}$ size causing mass effect over cauda equina and conus medullaris, no For aminal extension.
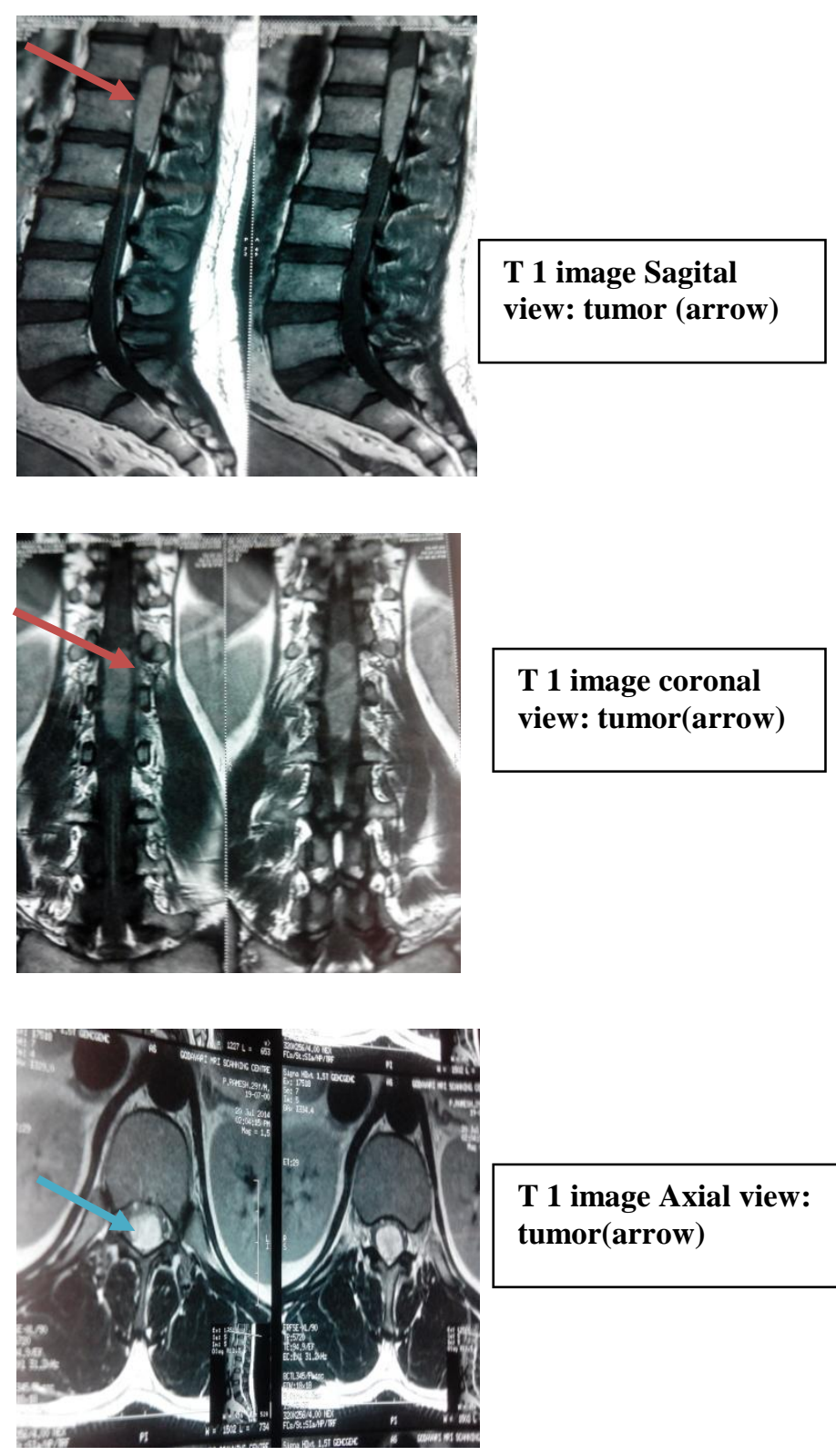

T 1 image Axial view: tumor(arrow)

\section{Management}

Patient was electively posted for surgeryT12- L1 laminectomy and excision of mass lesion done. Mass lesion was sent for Histopathogy studies.

\section{Intra-op findings-}

- Mass lesion was totally Intradural \& Extramedullary.

- No intramedullary component.
- Cord or cauda equina not involved.

- Mass was firm in consistency.

- Total excision done.

- Surgery uneventful.

\section{Diagnosis after Surgery}

As per intra op findings and co-relation with imaging studies it moreover goes in favor of SCHWANOMA as first diagnosis.

\section{Post op period}

- Post op patient recovered well

- No deficit, discharged on day 3 of surgery

- Totally pain relief, no radiculopathy, mobilized well

- After 15 days follow up- no urinary complaints also, he was absolutely free of any complaints.

\section{Histopathology}

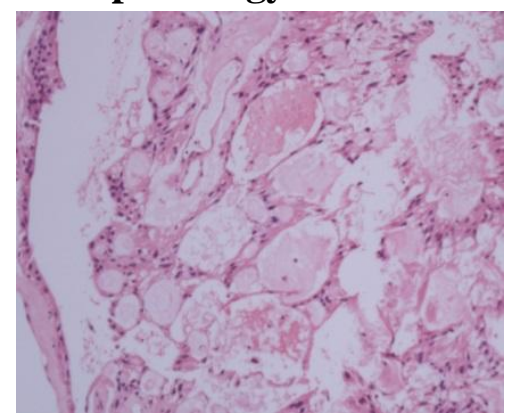

H \& E STAININNG

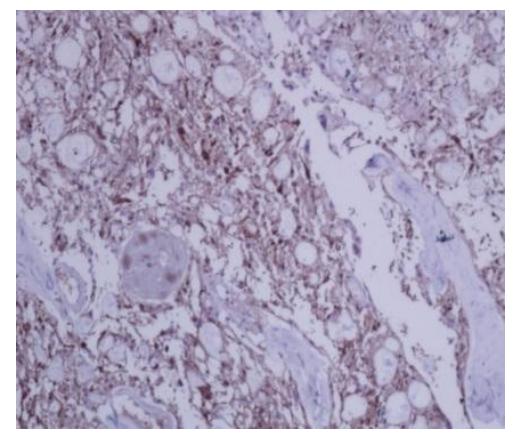

S-100 strong diffuse positivity

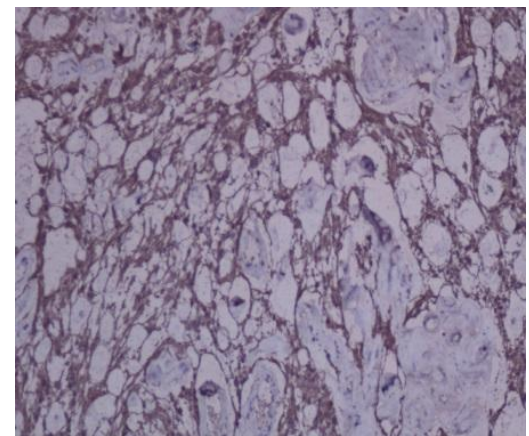

GFAP strong diffuse positivity 


\section{JMSCR Vol||05||Issue||08||Page 26382-26384||August}

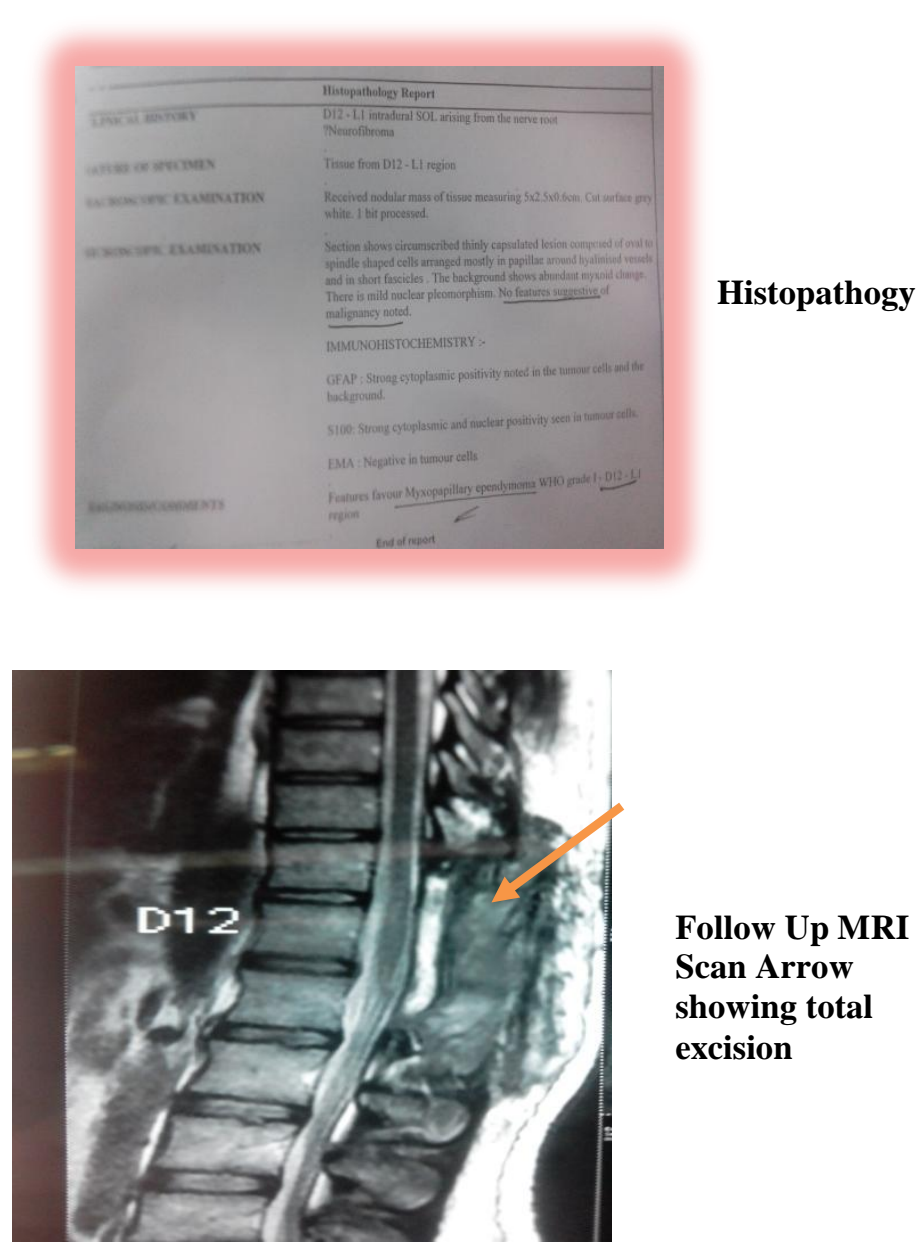

\section{Conclusion}

Thus, our clinical examination and imaging findings along with intraoperative findings were towards Schwannoma as our diagnosis. But after through histopathological examination it was found to be Myxopapillary Ependymomaas our final diagnosis. This is a rare presentation with rare location in spinal cord. This tumor is having good prognosis in future.

\section{References}

1. Jarvik JG, Deyo RA. Diagnostic evaluation of low back pain with emphasis on imaging. Annals Internal Medicine. 2002; 137:586-97. [PubMed]

2. Choi JY, Chang KH, Yu IK, et al. Intracranial and spinal ependymomas: Review of MR images in 61 patients. Korean J Radiol. 2002;3:219228. [PMC free article] [PubMed]

3. Sakai Y, Matsuyama Y, Katayama Y, et al. Spinal MyxopapillaryEpendymoma:
Neurological deterioration in patients treated With $\quad$ surgery. Spine. 2009; 34:16191624. [PubMed]

4. Wippold FJ, Smirniotopoulos JG, Moran CJ, Suojanen JN, Vollmer DG. MR imaging of MyxopapillaryEpendymoma: Findings and value to determine extent of tumour and its relation to intraspinal structures. Am J Radiol. 1995; 165:1263-67. [PubMed]

5. Bagley CA, Wilson S, Kothbauer KF, Bookland MJ, Epstein F, Jallo GI. Long term outcomes following surgical resection of Myxopapillary ependymomas. Neurosurg Rev. 2009; 32:321-334. [PubMed]

6. Bavbek M, Altinors MN, Caner $\mathrm{HH}$, Bilezikci B, Agildere M. Lumbar MyxopapillaryEpendymoma mimicking neurofibroma. Spinal Cord. 2001；39:449452. [PubMed]

7. Sonneland PR, Scheithauer BW, Onofrio BM. Myxopapillary Ependymoma: A clinicopathologic and immunohistochemical study of 77 cases. Cancer. 1985; 56:88393. [PubMed] 